\title{
Atuação dos conselheiros tutelares nos casos de entrega de um filho para adoção
}

\section{Role of tutelary counselors in cases of delivery of a child for adoption}

\author{
Suane Pastoriza Faraj (orcid.org/0000-0002-8013-0213)' \\ Mariana Peripolli Antoniazzi (orcid.org/0000-0002-4538-9406)² \\ Aline Cardoso Siqueira (orcid.org/0000-0003-1430-9722) ${ }^{3}$
}

\begin{abstract}
Resumo
Este estudo objetivou conhecer a atuação de conselheiros tutelares nos casos de entrega voluntária para adoção. Sete conselheiros tutelares de um município do Rio Grande do Sul responderam a uma entrevista individual. Dentre os resultados, encontrou-se que as mulheres doadoras vivenciavam situação de vulnerabilidade social, como dificuldades econômicas, ausência de apoio familiar e do pai da criança. A atuação dos conselheiros diante dos casos de entrega consistiu em escutar e orientar as mulheres. Também buscaram garantir o acompanhamento psicológico e social da mulher e da criança a partir da articulação de recursos disponíveis no município. Nesse ponto, constatou-se a busca da mulher pelo anonimato traduzida na sua recusa pelo acompanhamento psicológico, o que poderia levar ao seu isolamento e à vivência de sofrimento sem apoio. Esta pesquisa ainda suscitou a discussão acerca da necessidade de um serviço especializado articulado às maternidades.
\end{abstract}

Palavras-chave: Adoção. Doação. Direitos humanos.

\begin{abstract}
This study aimed to know the role of tutelary counselors in cases of voluntary surrender for adoption. Seven tutelary counselors from a municipality in Rio Grande do Sul responded to an individual interview. Among the results, it was found that the women donors experienced a situation of social vulnerability, such as economic difficulties, absence of family support and child's father. The role of counselors in the face of surrender cases consisted of listening and guiding women. They also sought to ensure the psychological and social support of women and children based on the articulation of resources available in the municipality. At this point, the woman's search for anonymity translated into her refusal by psychological counseling was verified, which could lead to her isolation and the experience of

\footnotetext{
1 Universidade Federal de Santa Maria, Santa Maria, Brasil. E-mail: suanef@yhoo.com.br.

2 Universidade Federal de Santa Maria, Santa Maria, Brasil. E-mail: marinantoniazzi@hotmail.com.

3 Universidade Federal de Santa Maria, Santa Maria, Brasil. E-mail: alinecsiq@gmail.com.
} 
suffering without support. This research also raised the discussion about the need for a specialized service linked to maternity hospitals.

Keywords: Adoption. Donation. Human rights.

A entrega do filho para adoção após o seu nascimento é um fenômeno que causa muitas inquietações por parte da sociedade e do poder público. Muitos questionamentos surgem sobre os motivos da entrega do filho, quem são as mulheres, o que sentem, como vivem, entre outros. É importante considerar que nem toda mulher aceitará ser mãe. $\mathrm{Na}$ contemporaneidade, a maternidade é compreendida como um projeto, como uma escolha pessoal, e não mais como "definidor da identidade Feminina", como algo obrigatório de toda mulher (Barbosa \& Rocha-Coutinho, 2012). Nesse sentido, a mulher vem desempenhando novos papeis e se inserindo em novos espaços, como na esfera pública, no mercado de trabalho, podendo escolher ter uma profissão que contemple benefícios pessoais e prestígio profissional (Patias \& Buaes, 2012).

Embora o papel social da mulher se desvincule progressivamente do cuidado familiar e dos afazeres domésticos, a decisão de doar um filho ainda causa estranhamento na sociedade, podendo impactar a vida da progenitora de diversas maneiras, e representar, em muitos casos, uma vivência traumática que causa sofrimento (Brodzinsky \& Smith, 2014; Carr, 2000; Leão, Martins, Faraj, Siqueira, \& Santos, 2014; Motta, 2008). O Conselho Tutelar é o órgão de defesa do Sistema de Garantia de Direitos, responsável pela proteção de crianças e adolescentes. Por derivação, também se responsabiliza pela criança em gestação e pela mulher que se questiona sobre manter ou não o filho consigo (Brasil, 1990). Diante disso, a atuação de conselheiros tutelares, nos casos de entrega voluntária para adoção, é o foco desse estudo.

\section{Mulheres que entregam o filho para adoção: estigmas sociais e direitos humanos}

As mulheres que decidem entregar o filho para adoção, de forma legal ou ilegal, são alvo de críticas e consideradas indivíduos com sérios problemas sociais e pessoais. A 
sociedade não diferencia a entrega legal voluntária da entrega ilegal e abandono de incapaz (Martins, Faraj, Santos, \& Siqueira, 2015; Menezes \& Dias, 2011; Siqueira et al., 2015). A entrega legal e voluntária ocorre quando a mulher assina um documento de destituição de seu poder familiar junto ao Juizado da Infância e Juventude, abrindo mão do vínculo legal com o filho. A entrega ilegal, também chamada de direta e adoção à brasileira, consiste na prática de registrar um filho não biológico como seu, não passando pelos trâmites legais da adoção, o que pode consistir em um risco à proteção da criança (Fonseca, 2012; Martins et al., 2015; Menezes \& Dias, 2011 ; Villalta, 2011).

O abandono é considerado crime pelo Código Penal Brasileiro (Brasil, 1940), consistindo na ação de deixar o filho em um lugar inseguro, muitas vezes, sob risco de vida. São exemplos de abandono de incapaz situações comuns divulgadas cotidianamente, como o encontro de bebês recém nascidos em rios, corredores de prédios, porta de igrejas ou mesmo na porta de casas, evidenciando, por um lado, o desespero de uma mãe que se julga incapaz de cuidar e proteger o filho, e por outro, a ausência de informação sobre os trâmites legais da entrega voluntária para adoção.

Muitas vezes, são atribuídas às mulheres que renunciam o cuidado do filho características negativas e pejorativas, pois faz parte da tarefa o legado da maternidade. Historicamente, a mulher esteve incumbida da procriação, do cuidado aos filhos e dos afazeres domésticos (Ariès, 1981; Scavone, 2001). O amor incondicional, inato, natural e de natureza biológica tem sido alvo de críticas, como aquelas apresentadas por Badinter (1985), as quais entendem que o amor materno é fruto de uma construção social secular. Siqueira et al. (2015) argumentaram que, uma vez que a sociedade não compreende a renúncia da maternidade de uma mulher, o mito do amor materno ainda está evidentemente enraizado no imaginário social. Essas concepções sociais interferem na forma como as pessoas julgam as outras e agem diante de determinadas situações. O estudo de Martins et al. (2015), realizado com profissionais da saúde de duas maternidades de hospitais públicos, evidenciou a interferência de concepções sociais associadas ao mito do amor materno entre essas profissionais, pouco conhecimento sobre aspectos legais da entrega para adoção e a concepção de que entregar legalmente é abandonar. Além disso, foi constatado que essas profissionais doavam enxovais e suprimentos para bebês, assim como conduziam conversas 
informais comoventes para que a genitora desistisse de entregar o filho para adoção. $O$ julgamento presente nesses atos, associado à naturalização e à idealização da maternidade, tendem a dificultar a compreensão da ruptura do laço que liga mãe e filho (Menezes \& Dias, 2011 ; Villalta, 2011).

Ainda que o fenômeno ocorra há décadas, a literatura nacional a respeito do tema é escassa (Siqueira et al., 2015). As pesquisas apontam que as mulheres que entregam o filho para adoção são jovens, solteiras e com nível socioeconômico desfavorecido (Freston \& Freston, 1994; Leão et al., 2014; Souza \& Casanova, 2012). Leão et al. (2014), a partir de uma análise de seis processos judiciais de entrega de crianças, ocorridos no período de 2010 a 2013, em um Juizado da Infância e Juventude (IJ), apontaram que as mulheres que entregaram o filho para adoção estavam na faixa etária entre 18 e 37 anos, tinham nível de escolaridade entre o ensino fundamental e médio e condição socioeconômica desfavorecida. Freston e Freston (1994), a partir de entrevistas realizadas com 58 mulheres que entregaram seus filhos recém-nascidos, apontaram que elas tinham idade entre 20 e 29 anos e a maioria não havia completado o ensino fundamental. Além disso, a análise mostrou que as mulheres não tinham um trabalho definido, possuíam uma renda familiar baixa e que a gravidez era fruto de relações eventuais. Os resultados de Souza e Casanova (2012) foram semelhantes aos de Freston e Freston (1994) quanto à faixa etária da mãe e a relação instável com o pai da criança. Nessa perspectiva, os estudos nacionais vêm mostrando que os motivos da entrega estão relacionados, em especial, à falta de apoio familiar e do genitor da criança, à falta de condições socioeconômicas e à gravidez não planejada ou fruto de um abuso sexual ou de uma relação eventual (Freston \& Freston, 1994; Leão et al., 2014; Menezes \& Dias, 2011).

Embora a literatura internacional não seja escassa, pesquisas sobre a mãe biológica são menos abundantes se comparadas às pesquisas sobre a criança adotiva e família adotante (Brodzinsky \& Smith, 2014; DeSimone, 1996). Os estudos existentes partem da perspectiva da mãe doadora, do sofrimento vivido após a entrega do filho e no grande impacto negativo que essa decisão traz em sua vida, influenciando sua saúde física e mental, além da dificuldade de estabelecimento de um vínculo afetivo com o parceiro ou mesmo com seus filhos subsequentes (Brodzinsky \& Smith, 2014; DeSimone, 1996; Kim \& Davis, 
2003). As mulheres doadoras estão na faixa dos 30 anos e com filhos anteriores, e têm como principais motivos para a entrega a falta de condições financeiras e a ausência de apoio familiar e do pai da criança (Chippendale-Bakker \& Foster, 1996; Roby \& Matsumura, 2002). Pouco é conhecido sobre o manejo das situações de entrega pelos profissionais em contexto internacional. O estudo de Roby e Matsura (2002) entrevistou mães doadoras residentes das Ilhas Marshall (EUA) e encontrou presença de idealizações nessas mulheres, como a ideia de que o filho voltaria bem-sucedido para cuidá-la, além de falsas promessas e certa coerção advinda da agência de adoção.

Entregar um filho pode revelar uma atitude consciente e/ou um ato de proteção. A decisão da mãe, no Brasil, está amparada na Lei 12.010 (Brasil, 2009), que apesar de dispor sobre direitos das crianças e dos adolescentes, também contempla a mãe que toma a decisão de entregar o filho. A referida legislação trata a entrega como um direito da mulher e da criança, preconizando o acompanhamento psicológico e o acolhimento judicial às gestantes ou mães que decidirem entregar o filho para adoção. Também estabelece a obrigatoriedade do encaminhamento destas à Justiça da Infância e da Juventude (artigo 13 Incluído pela Lei $n^{\circ} 12.010$, de 2009) para que todos os procedimentos sejam tomados e; institui multa aos profissionais da saúde que não encaminharem de imediato aos órgãos judiciários os casos de mães que queiram entregar os filhos (Brasil, 2009). Ainda que a legislação já tenha completado uma década, são escassos os estudos científicos sobre o tema na realidade brasileira, especialmente sobre a atuação dos profissionais da área, como os conselheiros tutelares.

O único estudo realizado com profissionais de saúde apontou que, apesar de, na prática, as profissionais de saúde encontrarem dificuldade para manejar a situação de entrega, a maioria das participantes relatou conhecer os encaminhamentos que deveriam ser adotados (Faraj, Martins, Santos, Arpini, \& Siqueira, 2016). As equipes comunicavam os casos à assistente social das instituições de saúde, assim como ao Conselho Tutelar do município e ao sistema judiciário. O estudo de Leão et al. (2014) constatou que as mulheres que decidem pela entrega do filho para adoção são acompanhadas pelo Conselho Tutelar. No entanto, encontrou que na maioria dos casos essa participação não era consistente e efetiva, como é esperado de tal órgão. Dessa forma, as autoras identificaram que as 
mulheres não recebiam o acompanhamento e a assistência conforme preconizados na legislação.

O Conselho Tutelar é um dos principais órgãos de defesa, tendo como função principal zelar pelo cumprimento dos direitos da criança e do adolescente (Brasil, 1990). O Estatuto da Criança e do Adolescente (ECA, Brasil, 1990) fixa que compete ao Conselho Tutelar atender as crianças e adolescentes e aplicar as medidas previstas no art. 101; atender e aconselhar os pais ou responsáveis e aplicar as medidas preconizadas no art. 129; executar suas decisões podendo requisitar serviços públicos; tomar providências para que a medida estabelecida pela autoridade judiciária, dentre as previstas no art. 101, de I a VI para o adolescente autor de ato infracional, seja cumprida; a representação ao Ministério Público para efeito das ações de perda ou suspensão do poder familiar, depois de esgotadas as possibilidades de manutenção da criança ou do adolescente junto à família natural.

$\mathrm{Na}$ rede de proteção voltada à criança e ao adolescente, o Conselho Tutelar exerce uma função paradigmática, pois não oferece assistência e não executa nenhum programa, mas compete a ele tomar providências para que os direitos desses indivíduos sejam atendidos, zelando pelas condições de vida dos mesmos (Frizzo \& Sarriera, 2005). Nesse sentido, o Conselho Tutelar é compreendido por alguns estudiosos da temática como a "polícia das famílias" (Donzelot, 1980). O órgão é referenciado como um espaço onde também se reproduzem práticas de controle, normalização e punição das relações familiares. O estudo de Ferreira, Noronha, Guedes e Ferreira (2015) inferiu que a representação do Conselho Tutelar para a população e os profissionais de saúde é embasada nas intervenções invasivas e dramáticas, como o encaminhamento para a delegacia e Justiça. Evidenciou que muitos profissionais e famílias ainda veem os serviços como locais coercitivos e punitivos, apesar desse órgão desempenhar a função de garantir os direitos das crianças e dos adolescentes brasileiros.

O Conselho Tutelar deve ser acionado sempre que um direito é ameaçado ou violado. Sua atuação ocorre a partir da articulação com outros órgãos como Juizado da Infância e Juventude, Delegacias de Proteção, Ministério Público e também com Políticas Públicas da saúde, assistência e educação (Brasil, 1990; Faraj, Siqueira, \& Arpini, 2016). Nesse sentido, nos casos de entrega legal, os conselheiros devem acolher a mulher que vive o impasse de 
entregar ou não o filho, indicar lugares em que ela possa ter atendimento psicológico antes e após a decisão pela adoção e encaminhar o bebê para acolhimento institucional até que a mãe biológica assine em juízo a destituição do poder familiar e uma família habilitada para adoção seja acionada (Brasil, 2009). Assim, este estudo teve como objetivo conhecer a atuação dos conselheiros tutelares nos casos de entrega voluntária do filho à adoção e averiguar como os direitos da criança e da mulher são garantidos. Destaca-se ainda a atualidade e relevância dessa temática, que tem por fim evitar situações de abandonos de bebê, garantir a proteção à mulher e à criança e diminuir os números de adoção ilegal.

\section{Método}

\section{Delineamento e participantes}

Trata-se de um estudo qualitativo, de caráter descritivo e exploratório. Participaram sete conselheiros tutelares, cinco de sexo feminino e dois do masculino. Todos representantes das três unidades de Conselhos Tutelares de uma cidade do Rio Grande do Sul. Os critérios de inclusão foram: ser conselheiro tutelar há pelo menos seis meses e ter atendido pelo menos um caso de entrega voluntária para adoção. Não houve critérios de exclusão.

\section{Instrumento}

Foram realizadas entrevistas semi-estruturadas a fim de se obter em profundidade as experiências dos profissionais que atuaram nos casos de entrega, realizando-se uma troca dinâmica entre o entrevistador e o entrevistado, promovendo a coleta de informações baseada no livre discurso deste (Bleger, 1993). Os eixos que nortearam as entrevistas foram: percepção acerca do tema e das mulheres que entregam o filho para adoção e procedimentos do Conselho Tutelar diante dos casos de mulheres que entregaram o filho para adoção. As perguntas foram elaboradas a partir dos eixos norteadores, contemplando os objetivos da pesquisa. 


\section{Procedimentos e considerações éticas}

Essa pesquisa faz parte de um projeto maior que propôs investigar o fenômeno junto ao Juizado da Infância e Juventude, às mães doadoras, aos profissionais da saúde nas maternidades e aos conselheiros tutelares. O projeto foi submetido e aprovado pelo Comitê de Ética em Pesquisa com Seres Humanos via Plataforma Brasil (protocolo número CAAE 20284913.2.0000.5346). A pesquisa foi respaldada na Resolução 510/16 do Conselho Nacional de Saúde e na Resolução nº 016 do Conselho Federal de Psicologia (2000) que regulamentam a pesquisa em seres humanos. Após a aprovação pelo Comitê de Ética, os estudos foram realizados sequencialmente. A amostra foi selecionada por conveniência após os coordenadores dos Conselhos Tutelares debaterem com os demais conselheiros e indicarem dois ou três representantes de cada unidade, com os quais foram agendadas as entrevistas. No momento da entrevista, foi estabelecido o rapport, foram esclarecidos os objetivos da pesquisa e, por fim, foi solicitada a assinatura do Termo de Consentimento Livre e Esclarecido. Uma vez que o estudo tratou da atuação dos profissionais, foi considerado de risco mínimo, pois os questionamentos não mobilizaram emocionalmente os participantes. O benefício da realização do estudo está na possibilidade de dar voz a esses profissionais e trazer a público esse fenômeno pouco estudado. As entrevistas foram realizadas individualmente no local de trabalho dos participantes e com duração de aproximadamente uma hora e trinta minutos. Os participantes serão nomeados de P1, P2, P3, P4, P5, P6, P7, para que se possa assegurar o sigilo das identidades.

\section{Análise dos dados}

As entrevistas foram gravadas e posteriormente transcritas na íntegra e analisadas qualitativamente (Bardin, 1977/2011). Num primeiro momento, realizou-se uma análise detalhada de cada entrevista individualmente e num segundo período procedeu-se a análise da totalidade do material obtido com as entrevistas, considerando a frequência, a força discursiva e a repetição. Buscando pontos de aproximação entre as entrevistas e também aspectos que se mostraram divergentes, foram esboçadas as seguintes categorias: (1) 
Percepção dos conselheiros tutelares sobre as mulheres que entregam o filho para adoção;

(2) Procedimentos do conselho tutelar diante da decisão da entregado filho para adoção e;

(3) A articulação com outros órgãos, serviços e instituições e a oferta do atendimento psicológico.

\section{Resultados e discussão}

Percepção dos conselheiros tutelares sobre as mulheres que entregam o filho para adoção

Esta categoria abordou a percepção dos conselheiros tutelares sobre as mulheres que entregam o filho para a adoção, englobando os motivos para essa ação e os sentimentos implicados nessa decisão. Além disso, abordou a visão que a sociedade tem em relação às mulheres que optaram pela adoção dos filhos, a partir da visão dos conselheiros tutelares.

$\mathrm{Na}$ concepção dos entrevistados, diferentes fatores podem estar implicados no ato da entrega do filho para a adoção, entre eles, a delicada situação socioeconômica, o conflito conjugal, o abandono do pai da criança e a falta de apoio familiar e social. Isso pode ser observado nos relatos:

Sobre a decisão de entregar o filho, vem toda por conta de uma situação familiar, socioeconômica, problema de relacionamento com o marido, companheiro, esposo[...] (P1)

Situação financeira e a rejeição paterna, né... (P2)

Primeiro vem à questão econômica: "porque eu não tenho condição, eu não tive ajuda para criar o meu primeiro filho". O segundo motivo, se ela está trabalhando: "com quem eu vou deixar, quem vai cuidar para mim, minha mãe já disse que não cuida"[...] (P3)

A parte financeira, a parte de não ter condição de criar a criança. Pra mim, nas que eu vejo, olha 90\% é isso. É sem condições de manter a criança... (P5)

Ela não tinha condições financeiras, né? Estrutura dela mesmo e a questão financeira que ela não ia ter condições e ela decidiu entregar essa criança. (P7)

Os conselheiros tutelares sinalizaram também como motivo da entrega, uma gravidez fruto de uma situação de violência sexual ou de uma relação extraconjugal: 
É a questão parental né? Essa criança ser gerada por questões de parente ou uma questão extraconjugal, por exemplo, teve uma que eu percebi, ela não falou, não relatou, mas me pareceu que a criança era filha do avô né? Uma outra menina, teve um relacionamento fora do... [pausa] extraconjugal, né? Essa moça foi a questão que ela é garota de programa, ela não sabia quem era o pai. (P7)

Normalmente ou ela foi um relacionamento fora do casamento e o atual companheiro quando ela tem mais filhos não aceita, às vezes essa gestação, tem mães que escondem até... Mas às vezes, quando são vítimas de algum abuso né. (P6)

Pesquisas nacionais e internacionais corroboram esses resultados, demonstrando que a motivação é multifatorial (Brodzinsky \& Smith, 2014; Carr, 2000; Condon, 1986; DeSimone, 1996; Mello \& Dias, 2003; Faraj, Machado, Siqueira, \& Campeol, 2017; Freston \& Freston, 1994; Janus, 1997; Kim \& Davis, 2003; Landrine \& Klonoff, 1996; Leão, et al., 2014; Martins et al., 2015; Menezes \& Dias, 2011; Motta, 2008; Najman, Morrison, Keeping, Andersen, \& Williams, 1990; Roby \& Matsumura, 2002; Santos \& Weber, 2005). Os estudos de Martins et al. (2015), Roby e Matsumura (2002), Menezes e Dias (2011) e Brodzinsky e Smith (2014) evidenciaram que a carência de recursos financeiros, a falta de apoio familiar e do parceiro, como também o incentivo da avó e do pai da criança se fazem presentes na decisão da entrega do filho para adoção. O estudo de Leão et al. (2014), Menezes e Dias (2011) e Faraj, Machado, Siqueira e Campeol (2017) ainda indicaram como motivação a vivência de abuso sexual, problemas de saúde da mulher e a presença de sentimento de desamparo, medo e incapacidade de cuidar na mãe doadora. Nesse sentido, pode-se observar que na decisão da entrega está presente a questão econômica, juntamente com as vivências familiares e pessoais.

A partir dos relatos, pode-se identificar que alguns conselheiros tutelares acreditavam que as mulheres que entregaram o filho apresentavam sofrimento diante da entrega, estando fragilizadas:

Mas eu acredito que durante o período, após, ela deve ter sofrido um pouco, ou até muito mais. (P3)

É um sofrimento pra elas, né? Porque tipo assim, entregou um filho... Pode haver um arrependimento aí... (P2) 
A pesquisa realizada por Menezes e Dias (2011) confirmou sofrimento e arrependimento nas mães doadoras por terem entregue o filho. Além disso, as autoras encontraram amargura, insatisfação e infelicidade, apontando que tais sentimentos poderiam estar denunciando o desamparo que essas mulheres vivenciavam em suas realidades. Estudos internacionais apresentam dados semelhantes, os quais mostram que o impacto dessa decisão é negativo, pois há evidências de sofrimento nessas mulheres que, mesmo após anos da entrega, vivenciam altos níveis de ansiedade, problemas de autoestima, como também problemas físicos de saúde (Aloi, 2009; Brodzinsky \& Smith, 2014; Namerow, Kalmuss, \& Cushman, 1997).

Para os profissionais entrevistados, essas mulheres são condenadas pela sociedade, que ainda é preconceituosa e desconhece o direito das mulheres, como pode ser observado nos relatos:

A sociedade sempre vê como algo negativo, né. Reprime, condena né. Sempre vai ter que, aí entra a questão do planejamento, "porque tu não fez um planejamento familiar?". Então assim, sempre vai ser o aspecto negativo, né. (P3)

As pessoas julgam ela. "Já que não queria uma gravidez, já que não quer a gravidez, por que que não se cuidou? Por que que não usou algum método anticoncepcional? Por que que não evitou, entendeu? Por que que deixou acontecer, né?" Aí as pessoas têm essa visão. Julgam por esse sentido. (P2)

No entanto, duas conselheiras tutelares assinalaram que a entrega pode ser vista pela sociedade como positiva para a criança. Segundo o participante 2 e 6 respectivamente:

Tem duas visões. Tem a visão positiva e a visão negativa, né? A sociedade tanto discrimina como apoia, no sentido do positivo, né? Porque essa criança vai ter uma oportunidade de uma família que vai acolher, uma família que vai mediar toda uma questão de vínculos, né? Tanto vínculos afetivos... Dá uma oportunidade que, de repente, essa criança com a mãe biológica não ia ter... (P2)

A todo seu tempo, dá a oportunidade pra essa criança ter vida e não ser ela, a mãe, que vai criar então, às vezes a gente até ouve comentário que isso não deixa de ser um ato de amor em relação a esse filho né? Então assim ó, julgamento existe em todas as... Né? Situações vivenciadas. Eu acho que agora já existe outra visão nesse 
sentido né? As observações ou julgamento não são tão radicais como eram um tempo atrás, né? Hoje em dia já existe mais isso e é encarado de uma maneira que... De uma maneira mais light digamos assim, das pessoas não fazer tão, tanta severidade sabe? Esse julgamento. (P6)

Nessa perspectiva, a maioria dos conselheiros tutelares compartilhou a opinião que a entrega é um ato de amor. Essa concepção pode ser vista nos trechos a seguir:

Eu assim. Eu, para mim assim, como ser humano, não como conselheira no pensamento, eu acho um amor, um ato de amor no ato da entrega. Não acho assim, um ato de egoísmo, mas que aquela pessoa tá levando essa criança para alguém que vai dar melhores condições... (P3)

Justamente pra não haver uma rejeição pós, após o parto, com o desenvolvimento da criança, muitas vezes elas preferem a adoção, né? [...] E pra o filho ter uma oportunidade melhor de vida. (P2)

Os achados do estudo de Martins et al. (2015), com profissionais de saúde, também evidenciaram que a entrega de um filho para adoção foi vista como um ato de amor e coragem da mãe, que visa ao bem-estar da criança, devido à impossibilidade de cuidar do filho, embora em alguns profissionais ainda perdurava a concepção do mito do amor materno. Na entrega, a mãe consente o cuidado da criança a outras pessoas (Barbosa, 2011). Assim, mesmo com impossibilidades psíquicas, econômicas e/ou sociais, as mães desejam preservar a vida do filho, e dessa forma, entregam-no para adoção (Menezes \& Dias, 2011).

Outro dado relevante encontrado no estudo refere-se à percepção dos conselheiros tutelares de que as mulheres que entregam o filho para adoção não têm conhecimento dos seus direitos, como pode ser observado nas falas:

Se elas sabem dos direitos dela, não. (P5)

Não, não tem conhecimento nenhum. (P4)

Não. Falta muita informação. (P3)

$\mathrm{Na}$ visão dos entrevistados, as mães doadoras desconhecem a entrega como um direito legal. A Lei 12.010 de 2009 preconizou a entrega do filho para adoção como um direito da mulher e da criança. Estabeleceu que esta mãe deve ter apoio psicológico e acolhimento judicial diante da decisão da entrega. As diretrizes da nova legislação instituem 
que essa assistência deve ser ofertada desde a gestação até o período puerperal, ou seja, deve ser oferecida até que a mulher se reorganize física e psiquicamente para dar seguimento à sua vida (Brasil, 2009; Leão et al., 2014). Nesse sentido, o Conselho Tutelar tem papel fundamental para garantir os direitos da mulher e da criança, já que são responsáveis pela defesa dos direitos humanos.

\section{Procedimentos do Conselho Tutelar diante da decisão da entrega do filho para adoção}

Esta categoria apresenta os procedimentos do Conselho Tutelar diante de uma situação em que a mãe decide entregar o filho para adoção. Aborda as ações dos conselheiros tutelares quando tomam conhecimento de uma situação de entrega, durante a decisão e após a entrega.

De acordo com os conselheiros tutelares entrevistados, as mães que querem entregar o filho para a adoção chegam ao órgão de três maneiras diferentes: (1) espontânea, (2) por uma denúncia ou (3) encaminhada do hospital em que deu à luz a criança, sendo essa última forma a mais comum. Os profissionais entrevistados sinalizaram que tanto as mães que chegaram ao conselho tutelar quanto os profissionais de saúde que solicitaram o atendimento do órgão de proteção queriam resolver de maneira rápida a entrega, como se este ato fosse proibido e criminoso. Esse dado evidencia que a entrega ainda não é aceita e encarada como algo possível, como um direito da mulher e da criança.

Quanto aos procedimentos, a partir dos relatos dos conselheiros tutelares, pode-se identificar diversas intervenções nas situações de entrega. A escuta e a orientação são os primeiros procedimentos realizados no caso de uma mãe que manifesta o desejo de entregar o filho para adoção. Pode-se averiguar que a escuta envolve saber os motivos da entrega e investigar se existe família ampliada, se o pai tem interesse em registrar e assumir a criança. Orientar refere-se ao ato de informar que a entrega é definitiva, que a criança fará um novo registro, que a mãe biológica não poderá ter informações sobre a criança e que existe uma legislação para esta situação que será seguida pelos conselheiros tutelares e pela rede de proteção. Esses procedimentos podem ser observados a partir dos relatos: 
Primeiro tu vai dizer "mãe, tu quer, por qual motivo? Quais as razões que você não quer ficar o bebê? Vamos tentar, a família, algumas coisas?" A gente vai ter que fazer umas perguntas, explicar os procedimentos de momento né, que esta mãe, embora ela tenha esse bebê, ela primeiro tem que ter uma certidão de nascimento...

A gente chama essa mãe aqui, realmente pra ter a confirmação que ela não quer, entendeu, a maternidade, que ela concorda com a adoção. E aí a gente pergunta se tem alguém da família que queira. (P2)

[...] a gente procura conversar com ela e orientar [...] (P5)

Chega essa demanda aqui no conselho, o que que se faz? A gente faz o questionamento né? Tenta procurar saber um pouco da questão, né? Da vida, como é que foi, questão paterna, se existe o conhecimento da questão paterna... (P7)

Os conselheiros tutelares apontaram que o intuito dessas intervenções é despertar uma reflexão:

Olha, eu questiono bem antes. Até para despertar reflexão. Acho que a função do conselheiro tutelar é... ela é técnica no sentido de lei, ECA, preciso conhecer bem essa lei e dominar ela, código civil também. Mas, ela é uma função tanto filosófica digamos, de despertar as consciências. O conselho tutelar não resolve o problema das pessoas... Então a função do conselheiro tutelar, eu vejo assim, é despertar consciência, é dizer o caminho tecnicamente onde a pessoa pode ir, o que está certo, o que está errado. E despertar a consciência dela, onde ela pode estar errando. Sem acusar, a gente não é polícia, não é órgão de acusação, é um órgão de orientação. $(\mathrm{P} 1)$

O estudo documental realizado por Leão et al. (2014) verificou que os conselheiros tutelares acompanham as mulheres que decidem entregar o filho para a adoção. No entanto, as autoras mostraram que em apenas um dos casos analisados o acompanhamento do conselheiro envolveu escuta, orientações e o acompanhamento no hospital e na audiência judicial. O conselheiro tutelar se apropriou do contexto social e familiar da mulher e buscou recursos na rede de atendimento municipal para amparar o bebê e a mãe, corroborando os dados desse estudo. No entanto, em outros processos analisados, a participação do conselho tutelar não foi consistente como a esperada. Dessa forma, ainda que em um caso 
tenha se observado uma atuação compatível com a legislação, em outros casos, as mães não receberam um acompanhamento e assistência conforme estabelecido na lei, evidenciando que os conselheiros precisam estar em sintonia entre si e com a legislação vigente.

A pesquisa realizada por Ferreira et al. (2015) demonstrou que a orientação das famílias estava entre as intervenções mais aplicadas pelos conselheiros tutelares. As famílias percebiam o acolhimento, o apoio emocional, o esclarecimento de dúvidas, o trabalho em rede e a garantia dos direitos das crianças, como experiências positivas do acompanhamento pelo Conselho Tutelar. Entretanto, as famílias analisaram como experiências negativas intervenções que não englobavam as demandas; o desacordo das decisões tomadas pelos conselheiros tutelares; as dificuldades nas dinâmicas de trabalho e; a pouca compreensão dos papéis institucionais desempenhados na rede de atendimento.

Para os profissionais que participaram do estudo, acompanhar a mãe para fazer o registro da criança também é uma atribuição do Conselho Tutelar. Destacaram que, após o registro da criança no cartório, o próximo procedimento é informar ao Juizado da Infância e Juventude:

Eu comunico então à Vara da Infância que tenho uma mãe que quer entregar. (P3)

A gente comunica o juiz, manda relatório. E tão logo o juiz chama essa mãe lá. (P2)

É nosso papel oficializar tudo isso... fazer esse encaminhamento, encaminhar pra cá, encaminhar pra defensoria pública, encaminhar pro Ministério Público. (P5)

Essa comunicação, de acordo com os entrevistados, é realizada via telefone e relatório. Após a informação ao judiciário, geralmente ocorre a audiência judicial em que a genitora deve verbalizar a decisão de entregar o filho para a adoção, momento em que os profissionais do Conselho acompanham a mãe. As atribuições específicas do Conselho Tutelar estão descritas no Estatuto da Criança e do Adolescente (Arts. 95 e 136, Brasil, 1990). Entre elas pode-se destacar: atender as crianças e/ou os adolescentes e aplicar medidas protetivas (Art. 101 do ECA); atender e aconselhar os pais ou responsável e também aplicar medidas de proteção (Art. 129 do ECA); promover a execução de suas decisões; encaminhar ao Ministério Público notícia e fato que constitua infração administrativa (Arts. 245 a 258) ou penal (Arts. 228 e 244) contra os direitos da criança ou do adolescente; 
encaminhar à autoridade judiciária os casos de sua competência e; requisitar certidões de nascimento e de óbito de criança ou de adolescente quando necessário (Brasil, 1990).

Quanto ao acompanhamento da mãe após a entrega da criança para adoção, os profissionais relataram que se colocam à disposição, no entanto, foram unânimes em afirmar que o Conselho Tutelar a acompanha apenas se solicitado ou se a mãe for adolescente:

[...] então me coloco à disposição, se ela precisar de um acompanhamento, de uma conversa, ela vem aqui. (P1)

Entrega, tem o momento da audiência e após esse vínculo se quebra, né. A não ser que futuramente ela possa ter uma outra criança e venha acontecer que o conselho acaba novamente dando um atendimento. (P3)

Não, a gente não tem mais porque ter vínculo, né? A não ser que ela tenha outros filhos, aí né? A gente entregou e se ela não quer vínculo mais, muitas nem querem contato com o conselho tutelar! Então a gente não força nada, entendeu? Se ela quiser ajuda, a gente deixa bem livre, né? (P2)

[...] nada pelo Conselho Tutelar, a não ser que seja adolescente, aí continua o acompanhamento, né. (P4)

No estudo, ficou evidente que após a mãe entregar o filho para a adoção, existe um pedido de silêncio por parte desta diante da situação, como se a entrega não fosse permitida. Nessa atitude parecem estar implicados diversos aspectos, como o julgamento da sociedade, a falta de informação a respeito dos seus direitos e o segredo familiar.

\section{A articulação com outros órgãos, serviços e instituições e a oferta de atendimento psicológico}

Esta categoria aborda a percepção dos conselheiros tutelares em relação à articulação com outros órgãos e serviços de atendimento, diante dos casos em que a mulher decide entregar o filho para adoção. Os participantes afirmam que buscam serviços de Psicologia do município para encaminhar as mulheres que decidiram entregar o filho para a adoção, para o companheiro, ou ainda, a um familiar. As demandas encaminhadas não dizem respeito 
somente às repercussões da entrega para adoção. Se existe uma situação de saúde mental, o encaminhamento é feito para o Centro de Atenção Psicossocial (CAPS), ou se a questão for de vulnerabilidade social, a família é encaminhada para o Centro de Referência de Assistência Social (CRAS). É importante inferir que não existe uma única definição para o termo vulnerabilidade social. O termo abrange aspectos epidemiológicos e individualizantes, bem como, aspectos demográficos e socioeconômicos da população, abarcando as condições de saúde, o acesso aos serviços básicos, à privação de direitos e a carência de recursos materiais (Scott, Prola, Siqueira, \& Pereira, 2018).

A articulação mais evidente dos conselheiros tutelares ocorre entre os profissionais das maternidades públicas e o Juizado da Infância e Juventude. Observa-se que a articulação acontece no momento em que o hospital entra em contato com o conselheiro tutelar ou quando este vai até o hospital, após o nascimento da criança. Os enfermeiros e/ou assistentes sociais do hospital trocam informações com o Conselho Tutelar e este órgão realiza os procedimentos necessários.

No que se refere especificamente ao encaminhamento da mulher para atendimento psicológico, os profissionais acreditavam que o atendimento é importante para elas. Para eles, a decisão de abrir mão de cuidar do filho é algo impactante e marcante para uma mulher, à qual estavam associados muito sofrimento e problemas psicossociais, como falta de moradia, emprego, conflito familiar, ausência de apoio social, entre outros. A importância do profissional de psicologia nos casos de entrega também foi apontada em um estudo realizado com profissionais da saúde (Faraj et al., 2016) e com mães doadoras (Faraj et al., 2017; Namerow et al., 1997). A maioria dos profissionais verbalizou que realizava o encaminhamento da mulher para um serviço do município que conta com o profissional de psicologia, ou o solicitava para o judiciário. Entretanto, os conselheiros tutelares sinalizaram que as mulheres não buscavam nem aceitavam esse atendimento:

Quando a mãe entrega, a gente até faz esse encaminhamento pro psicólogo, se a mãe não quer ir, não quer ir. Paciência. Entendeu? (P5)

Não, não querem, não querem pela questão justamente do sigilo né? Bom, eu entreguei meu filho não quero que ninguém saiba, porque eu vou fazer um atendimento psicológico? (P7) 
Os entrevistados verbalizaram que diante da recusa das mães, não possuíam recursos para agir:

Se eu faço um encaminhamento pra uma mãe que sai do hospital, que vai lá, eu faço um encaminhamento pra um psicólogo, pro CRAS, e ela evade desse acompanhamento, eu não vou... eu não tenho subsídio suficiente "não tu vai ter que retornar", porque ela é maior de idade e aí o vínculo dela com o conselho acaba no momento em que ela deu a luz, né? (P6)

A partir das falas, pode-se observar o quanto é difícil para a mulher que entrega o filho para adoção falar sobre essa situação, optando assim pelo silêncio, ou seja, pelo anonimato, que por sua vez alimenta concepções sociais pejorativas. Essa reflexão é feita por Fonseca (2012), que apontou que as "mães abandonantes" são uma das categorias mais esquecidas da história, pois o anonimato a que estão sujeitas impossibilita conhecê-las e articular redes de atendimento que possibilitem seu acolhimento. Diante dessa ponderação, pode-se inferir a ausência de políticas públicas de proteção como uma das condições de entrega. Nesse sentido, faz-se necessário resgatar essas mulheres da invisibilidade social através de políticas de saúde e de assistência, garantindo seus direitos (Martins et al., 2015; Siqueira et al., 2015).

Embora houvesse o encaminhamento e a recusa de muitas mães, também foi constatado que o município não ofertava nenhum serviço especializado na sua rede de atendimento para as mulheres que entregam o filho para adoção. A fala a seguir denuncia a falta de apoio psicológico e social a essas mulheres:

E o que a gente acredita que falta é no pós né, pra essas mães, um trabalho psicológico pra essas mães, pra que elas tentem administrar melhor essa questão né? De vínculo, da decisão, administrar melhor a decisão, a gente acredita ainda falta, porque Conselho Tutelar não tem essa estrutura né? Aqui dentro a gente não é psicólogo, a gente não é assistente social. A gente não tem como, como suprir essa demanda que elas trazem né? (P7)

Outra conselheira apontou que deveria ser criado no município um serviço específico para atender essas mulheres. Leão, Silva e Serrano (2012) apontaram que a oferta de um espaço que possibilita a elaboração de suas vivências é importante para as mulheres que 
decidem pela entrega do filho à adoção, assim como a implantação de políticas públicas que busquem garantir o apoio, tanto jurídico quanto emocional. Como um modelo de atendimento, pode-se citar o serviço de psicologia da maternidade de um hospital do Estado de Santa Catarina. O serviço desenvolve um trabalho intitulado maternagem, que consiste no acolhimento dos bebês nascidos na instituição, abandonados ou entregues para adoção e na oferta de suporte à genitora que decide entregar o filho no ambiente hospitalar a partir de conversas entre a psicóloga e a mãe a respeito de todos os aspectos que envolvem essa decisão. Nessas conversas, se prioriza uma postura compreensiva e receptiva de atender ao desejo da mãe, encaminhando o bebê já para a maternagem e, posteriormente, à mãe adotiva/substituta, sem a necessidade de acolhimento institucional (Boing \& Crepaldi, 2004). Assim, pensar em ações articuladas e serviços para acolher e promover assistência psicológica e jurídica a essas mulheres é importante para garantir os seus direitos e os da criança (Leão et al., 2014).

\section{Considerações finais}

Este artigo propôs aprofundar o conhecimento sobre o fenômeno da entrega para adoção do ponto de vista de conselheiros tutelares, em especial suas concepções e os procedimentos tomados diante da renúncia da maternidade. Os dados fornecidos pelos profissionais entrevistados evidenciaram a complexidade do fenômeno, apontando a fragilidade das mulheres, suas condições precárias, ausência de apoio social e que muitas vezes vivenciam o peso de sua decisão sozinhas por não aceitarem acompanhamento, ainda que não exista um serviço especializado na realidade pesquisada. A fragilidade pessoal encontrada demonstra que essas mães precisam de serviços atuantes e que forneçam suporte, para que não escolham o anonimato e o sofrimento no exílio. A sociedade ainda condena as mulheres que renunciam a maternidade, muitas vezes através de preconceitos, e por não ter os devidos esclarecimentos sobre o direito de a mulher entregar o filho para adoção. Contudo, essa situação somente começará a mudar quando elas exercerem sua cidadania e exigirem que seus direitos sejam atendidos; assim a sociedade passará a refletir com o devido cuidado sobre esse fenômeno. 
Esse estudo também demonstrou o eminente papel que o Conselho Tutelar possui nesses casos. O conselho é um órgão de referência, e por isso precisa garantir os direitos das mulheres que desejam entregar os filhos para adoção sem julgamentos. Com os resultados, percebeu-se que existem etapas significativas para a entrega do filho para adoção. Em um primeiro momento, a escuta e a orientação se tornam fundamentais nesse processo. Conhecer o motivo que leva a mãe a esse ato, bem como orientá-la sobre o processo estão na função dos conselheiros tutelares. Além disso, acompanhar a mãe no registro do filho e informar ao Juizado da Infância e Juventude que ela não deseja ficar com a criança também fazem parte dos procedimentos dos conselheiros tutelares. Ainda que as mulheres tenham optado pelo anonimato, o suporte social livre de julgamento moral e preconceito ofertado pelos conselheiros e em sintonia com a legislação é fundamental para que elas comecem a superar o impacto da decisão.

Para os conselheiros tutelares conseguirem atender e auxiliar essas mulheres, é necessária a articulação com outros serviços disponíveis no Município. Porém, nesse estudo, ficou claro que os únicos serviços que davam algum suporte especializado foram o hospital, onde a mulher ganhava o filho, e o Juizado da Infância e Juventude, onde a mulher falava sobre a sua vontade de entregar o filho para adoção. Todos os suportes existentes cessavam após a entrega, contribuindo para o isolamento e percepção de ausência de apoio à mãe doadora, fatores que podem impactar a saúde mental.

Através do relato dos entrevistados, pode-se observar que estes têm conhecimento das suas atribuições no processo de entrega de uma criança para adoção. Pode-se averiguar que existe a preocupação em conhecer as condições da família ampliada e do pai da criança. Ainda que o estudo esteja amparado no auto-relato dos profissionais sobre suas próprias atuações, o que pode ser considerado uma limitação do estudo, observou-se que os conselheiros demonstraram estar cientes do andamento legal dos casos. Pode-se identificar também que, os conselheiros tutelares, a partir da escuta e orientação, buscavam a reflexão da mãe, para que a decisão não fosse precipitada. A importância do cumprimento da Lei nos casos de entrega foi percebida nos discursos dos conselheiros tutelares. O trabalho conjunto e articulado foi identificado como necessário diante da complexidade do fenômeno. 
Notou-se que, embora os conselheiros tenham mencionado verificar a situação paterna, na atual legislação não consta a oitiva do pai como obrigatória para a destituição do poder familiar nem prazo mínimo entre a entrega legal e a adoção por uma família habilitada na fila de espera. Entende-se que a legislação se mantem em constante atualização, e espera-se que esses aspectos possam ser construídos, norteando a prática dos conselheiros tutelares.

Estudos sobre o fenômeno de entrega do filho para adoção devem ser fomentados na realidade brasileira para que a sociedade reconheça que essas mulheres possuem tal direito. Também, para que os profissionais que as auxiliam possam estar preparados e amparados para fornecer escuta e informações pertinentes em cada caso. Por ainda ser um fenômeno pouco pesquisado no Brasil, são poucos os estudos encontrados a respeito desse tema. É necessário que a mulher seja respeitada por sua escolha, e por isso deve haver mais informações a respeito da entrega voluntária do filho. Consideram-se fundamentais ações para promover assistência às mães doadoras, principalmente no sentido de tirá-las do anonimato e da exclusão. Por fim, é importante possibilitar à sociedade entender e aceitar a decisão da mulher que entrega seu filho, visto que é seu direito e está em sintonia com o princípio do melhor interesse para a criança. A maneira como os conselheiros tutelares compreendem a maternidade e a situação do impasse vivenciado pela mãe, como também sua atuação enquanto órgão de defesa dos direitos da criança e do adolescente evidencia a possibilidade de protegê-los de violação dos direitos, promovendo acolhimento para a mãe. Devido ao estudo ter caráter exploratório, por conta da ausência de investigações no tema junto aos conselheiros tutelares, entende-se que o auto-relato pode ser considerado uma das limitações do estudo. Com isso, sugere-se que os próximos estudos possam utilizar a triangulação dos dados, como também ampliar a amostra, para que se obtenha um panorama do fenômeno na atualidade.

\section{Referências}

Aloi, J. A. (2009). Nursing the disenfranchised: women who have relinquished an infant for adoption. Journal of Psychiatric and Mental Health Nursing, 16, 27-31. https:// doi.org/10.1111/j.1365-2850.2008.01324.x 
Ariès, P. (1981). História Social da Criança e da Família. Rio de Janeiro: LTC.

Badinter, E. (1985). Um amor conquistado: O mito do amor materno. Rio de Janeiro: Nova Fronteira.

Barbosa, A. P. S. (2011). Mulher monstro: Violência contra a mulher que entrega o filho em adoção e a Lei 12.010/09. Anais eletrônicos do I/ Simpósio Gênero e Políticas Públicas da Universidade Estadual de Londrina (pp. 1-8). Londrina: Universidade Estadual de Londrina. http://www.uel.br/eventos/gpp/pages/arquivos/Ana\%20Paula.pdf

Barbosa, P. Z., \& Rocha-Coutinho, M. L. (2012). Ser mulher hoje: a visão de mulheres que não desejam ter filhos. Psicologia \& Sociedade, 24(3), 577-587. https://www.scielo.br/pdf/psoc/v24n3/11.pdf

Bardin, L. (2011). Análise de Conteúdo (edição revisada, atualizada e ampliada). Lisboa: Edições 70. (Obra original publicada em 1977)

Bleger, J. (1993). Temas de psicologia: Entrevista e grupos. São Paulo: Martins Fontes.

Boing, E., \& Crepaldi, M. A. (2004). Os efeitos do abandono para o desenvolvimento psicológico de bebês e a maternagem como fator de proteção. Estudos de Psicologia (Campinas), (21), 211-226. https://doi.org/10.1590/S0103-166X2004000300006

Brasil, República Federativa do Brasil. (1940). Decreto-lei $n^{\circ} 2.848$, de 7 de dezembro de 1940. Dispõe sobre o Código Penal. Brasília, DF: Presidência da República. http://www.planalto.gov.br/ccivil_03/Decreto-Lei/Del2848.htm

Brasil, República Federativa do Brasil. (1990). Lei $n^{\circ}$ 8.069, de 13 de julho de 1990. Dispõe sobre o Estatuto da Criança e do Adolescente e dá outras providências. Brasília, DF: Presidência da República. http://www.planalto.gov.br/ccivil_03/leis/l8069.htm

Brasil, República Federativa do Brasil. (2009). Lei $n^{\circ}$ 12.010, de 29 de julho de 2009. Dispõe sobre adoção; altera as Leis $\mathrm{n}^{\circ} \mathrm{s} 8.069$, de 13 de julho de 1990 - Estatuto da Criança e do Adolescente, 8.560, de 29 de dezembro de 1992; revoga dispositivos da Lei $\mathrm{n}^{\circ}$ 10.406, de 10 de janeiro de 2002. Brasília, DF: Presidência da República. http://www.planalto.gov.br/ccivil_03/_ato2007-2010/2009/lei/112010.htm

Brodzinsky, D., \& Smith, S. L. (2014) Post-placement adjustment and the needs of birthmothers who place an infant for adoption. Adoption Quarterly, 17(10), 165-184. https://doi.org/10.1080/10926755.2014.891551

Carr, M. J. (2000). Birthmothers and subsequent children: The role of personality traits and attachment history. Journal of Social Distress and the Homeless, 9(4), 339-340. https: / / doi.org/1053-0789/00/1000-0339

Chippindale-Bakker, V., \& Foster, L. (1996). Adoption in the 1990s: Sociodemographic determinants of biological parents choosing adoption. Child Welfare, 75(4), 337-355.

Condon, J. (1986). Psychological disability in women who relinquish a baby for adoption. The Medical Journal of Australia, 144, $117-119$.

Conselho Federal de Psicologia. (2000). Resolução CFP $n^{\circ}$. 016/2000 de 20 de dezembro de 2000. Brasília, DF: CPF.

Conselho Nacional de Saúde. (2016). Resolução do Conselho Nacional de Saúde 510/16. Brasília, DF: CNS. http://conselho.saude.gov.br/resolucoes/2016/Reso510.pdf.

DeSimone, M. (1996). Birth mothers loss: Contributing factors to unresolved grief. Clinical Social Work Journal, 24(1), 65-76. https://doi.org/10.1007/BF02189942 
Donzelot, J. (1980). A Polícia das famílias (M. T. C. Albuquerque, Trad.). Rio de Janeiro: Edições Graal.

Faraj, S. P., Martins, B. M. C., Santos, S. S., Siqueira, A. C., \& Artpini, D. M. (2016). "Quero Entregar meu Bebê para Adoção": O Manejo de Profissionais da Saúde. Psicologia: Teoria e Pesquisa, 32(1), 151-159. https://doi.org/10.1590/0102-37722016011998151159

Faraj, S. P., Siqueira, A. C., \& Arpini, D. M. (2016). O Atendimento Psicológico no Centro de Referência Especializado da Assistência Social e a visão de operadores do direito e conselheiros tutelares. Estudos de Psicologia (Campinas), 33(4), 757-766. https: / / doi.org/10.1590/1982-02752016000400018

Faraj, S. P., Machado, M. S., Siqueira, A. C., \& Campeol, A. R. (2017). "Doeu muito em mim!": Vivência da entrega de um filho para adoção na visão de mães doadoras. Estudos $e$ Pesquisa em Psicologia, $17(2), 475-493$.

Ferreira, A. L., Noronha, D. R., Guedes, L. G., \& Ferreira, S. P. (2015). O ponto de vista da família de crianças vítimas de violência perante a ação do Conselho Tutelar. Revista de Pediatria SOPERJ, 15(2), 10-15.

Fonseca, C. (2012). Mães "abandonantes": Fragmentos de uma história silenciada. Revista Estudos Feministas, 20(1), 13-32. https://doi.org/10.1590/S0104026X2012000100002

Freston, Y. M. B., \& Freston, P. (1994). A mãe biológica em casos de adoção: Um perfil da pobreza e do abandono. In F. Freire (Ed.), Abandono e adoção: Contribuições para uma cultura da adoção (pp. 81-90). Curitiba: Terre des Hommes.

Frizzo, K. R., \& Sarriera, J. C. (2005). O conselho tutelar e a rede social na infância. Psicologia USP, 16(4), 175-196. https://doi.org/10.1590/S0103-65642005000300009

Janus, N. G. (1997). Adoption counseling as a professional specialty area for counselors. Journal of Counseling and Development, (75), 266-274. https://doi.org/10.1002/j.1556-6676.1997.tb02341.x

Kim, E., \& Davis, K. (2003). Conceptualizing unmarried motherhood in South Korea: The role of patriarchy and Confucianism in the lives of women. Journal of Social Work Research \& Evaluation, 4(1), 107-120.

Landrine, H., \& Klonoff, E. A. (1996). Traditional African-American family practices: Prevalence and correlates. Western Journal of Black Studies, 20(2), 59-62.

Leão, F. E., Martins, B. M. C., Faraj, S. P., Siqueira, A. C., \& Santos, S. S. (2014). Mulheres que entregam seus filhos para adoção: Um estudo documental. Revista Subjetividades, 14(2), 276-283. http://pepsic.bvsalud.org/pdf/rs/v14n2/10.pdf

Leão, L. C. S., Silva, C. G. C., \& Serrano, S. A. (2012). A entrega de um filho em adoção e as vicissitudes de ser mãe. Psicologia para América Latina, 23, 28-46. http:/ /openaccess.city.ac.uk/12495/1/ulapsi.pdf

Martins, B. M. C., Faraj, S. P., Santos, S. S., \& Siqueira, A. C. (2015). Entregar o Filho para Adoção é Abandoná-lo? Concepções de Profissionais da Saúde. Psicologia Ciência e Profissão, 35(4), 1294-1309. https://doi.org/10.1590/1982-3703002352013

Mello, I. S. P. B., \& Dias, C. M. S. B. (2003). Percepção de Homens e Mulheres Acerca de Quem Entrega um Filho para Adoção. Psicologia Ciência e Profissão, 21(3), 76-83. https:// doi.org/10.1590/S1414-98932003000100011 
Menezes, K. L., \& Dias, C. M. S. B. (2011). Mães doadoras: Motivos e sentimentos subjacentes à adoção. Revista Mal-estar e Subjetividade, 17(3), 933-960. http://pepsic.bvsalud.org/pdf/malestar/v11n3/03.pdf

Motta, M. A. P. (2008). Mães abandonadas: A entrega de um filho em adoção. São Paulo: Cortez.

Najman, J. M., Morrison, J., Keeping, D., Andersen, M., \& Williams, G. (1990). Social factors associated with the decision to relinquish a baby for adoption. Community Health Studies, 14(2), 180-189.

Namerow, P. B., Kalmuss, D., \& Cushman, L. F. (1997). The consequences of placing versus parenting among young unmarried women. Marriage \& Family Review, 25, 175-197. https://doi.org/10.1300/J002v25n03_04

Patias, N. D., Buaes, C. S. (2012). "Tem que ser uma escolha da mulher"! Representações de maternidade em mulheres não-mães por opção. Psicologia \& Sociedade, 24(2), 300306. https://doi.org/10.1590/S0102-71822012000200007

Roby, J. L., \& Matsumura, S. (2002). If I give you my child, aren't we family? A study os birthmothers participating in Marshall Islands-U.S. Adoptions. Adoption Quarterly, 5(4), 7-20. https://doi.org/10.1300/J145v5n4_2

Santos, C. D., \& Weber, L. N. D. (2005). O que leva uma mãe a abandonar um filho? In H. Guilhardi, \& N. C. Aguirre (Orgs.), Psicologia, Comportamento e Cognição (pp. 133146). Santo André: ESEtec.

Scavone, L. (2001). Maternidade: Transformações na família e nas relações de gênero. Interface: Comunicação, Saúde e Educação, 5(8), 47-60. https:// doi.org/10.1590/S1414-32832001000100004

Scott, J. B., Prola, C., Siqueira, A. C., \& Pereira, C. R. R. (2018). O conceito de vulnerabilidade social no âmbito da psicologia no Brasil: uma revisão sistemática da literatura. Psicologia em Revista, 24(2), 600-615. http://doi.org/10.5752/P.16789563.2018v24n2p600-615

Siqueira, A. C., Santos, S. S., Leão, F. E., Faraj, S. P., Martins, B. M. C., \& Campeol, A. R. (2015). Quem são as mulheres que entregam o filho para adoção na visão dos profissionais da saúde e do judiciário? In A. M. P. Caniato et al. (Orgs.), Psicologia Social, Violência e Subjetividade (pp. 260-273). Florianópolis: ABRAPSO. http://www.abrapso.org.br/download/download?ID_DOWNLOAD=476

Souza, H. P., \& Casanova, R. P. (2012). Adoção: O amor faz o mundo girar mais rápido. Curitiba: Juruá.

Villalta, C. (2011). Entregas, adopciones y dilemas en el campo de organismos destinados a la infancia. Estudos Feministas, 19(1), 103-130. https://doi.org/10.1590/S0104026X2011000100008

Recebido em: 6/7/2018

Aprovado em: $27 / 6 / 2019$ 